\title{
ABSTRACT:
}

In this paper, we draw on narrative correspondence from older male spousal caregivers and interviews with care providers from the voluntary and statutory sectors to explore how older male carers in the UK cope with and experience care-giving, the forms of support they draw upon, and how this impacts on their sense of self and identity as older men. We also consider how (or if) gender plays a part in shaping the forms of formal care support extended to male carers. We conclude, that how older men construct and perform care-giving, and how the wider family and community responds to older men as carers, can impact on how they perform masculinity. This in turn can contribute to a decline in their social networks and opportunities for sociability, leading to increased loneliness and social isolation. Such insights are important if we are to enrich our knowledge of the challenges they face, the coping mechanisms they employ, and the extent to which their support needs are met in their caring role.

KEYWORDS: Care-giving, older men, identity, narrative correspondence, masculinity, intersectionality 


\section{Care, coping and identity: older men's experiences of spousal care-giving.}

The UK population is rapidly ageing; and whilst many older people lead healthy and active lives - especially in early retirement - with increased age comes an increased risk of declining health and mobility (Milligan, 2009). Unpaid (family) carers plays a crucial role in supporting those who experience difficulties in undertaking activities of daily life. This task has historically been undertaken by women (ONS, 2013a), and whilst overall women still assume a greater proportion of the caring role than men, changes to this gendered landscape of care are occurring at older age. Recent analysis of the 2011 census for England and Wales, for example, reveals that $15.1 \%$ of the population over 65 years of age are male carers compared to $13.5 \%$ of women. Further, these older male carers (OMCs) are likely to undertake more hours of care-giving than do their female counterparts (ONS, 2013b) - a pattern that is evident across all three categories of unpaid care-giving measured by the UK census (i.e. 1-19 hours; 20-49 hours and 50 plus hours of care per week). This shifting landscape of care is not unique to the UK - a small, but growing body of work has highlighted an increase in older male care-giving across a range of countries from Europe to North America (see for example, Ducharme et al, 2006; Ribeiro and Paúl, 2007; Akpinar and Küçuküçlu, 2011; Eriksson et al, 2013). Further, as one recent systematic review concluded, research on OMCs experiences of care-giving remains relatively underdeveloped, especially in comparison to that focusing on female carers (Greenwood and Smith, 2015). Yet those studies that do focus on OMCs suggest that older men feel their needs and experiences of care-giving differently from older women (Baker and Robertson, 2008; Slack et al., 2014).

By and large, however, the gendered nature of OMC’s experiences often goes unquestioned (Eriksson et al, 2013). In those papers that do consider OMCs, it is often as part of a 
male/female comparison or examined as a descriptive variable (e.g. Arber and Ginn, 1995; Davidson et al, 2000; Dahlberg et al, 2007; del Bono et al, 2009), so fails to either conceptualise OMC's experiences or address potential variations within groups. Crocker Houde (2002) for example, highlighted the lack of studies differentiating between son and spouse/partner care-givers. Sandberg and Eriksson (2008) point to the lack of knowledge around both OMCs' experiences of care-giving, and the commencement and progression of their care-giving role. Others highlight a tendency for studies to focus on male care-giving within specifically defined illness categories such as Alzheimer's or other dementias (Ribeiro and Paúl, 2008; Akpinar and Küçuküçlu, 2011). Differences in outcome, dependent on the methodological approach used, have also been noted. A review by Baker and Robertson (2008) for example, reported that studies using surveys or interviews reveal highly gendered stereotyped emotions (with men disclosing pride and women disclosing affection) but this is less evident in more observational or diary-based studies. Such outcomes alert us to the potential for bias in which both studies and researchers can perpetuate gendered frames of reference and outcomes in support provided by carers (Calasanti \& King 2007; Greenwood and Smith, 2015).

This paper seeks to add to the relatively limited evidence base around the experiences of OMCs by drawing on a qualitative study undertaken with older male spousal carers and care providers (i.e. paid professionals involved in the assessment and delivery of care support by the statutory and third sectors). The overall aim of the study was to deepen knowledge about how OMCs cope with, and experience, care-giving, the forms of support they draw upon, and how this impacts on their sense of self and identity as older men. This is important if we are to enrich our understanding of the challenges they face, the coping mechanisms they employ, and the extent to which their support needs may vary in terms of facilitating their ability to 
successfully manage their care-giving role. By also engaging with care providers, we aimed to gain a clearer understanding of how (or if) gender plays a part in shaping the forms of formal care support extended to male carers.

\section{Method}

This qualitative study involved narrative correspondence with older male spousal carers and in-depth interviews with care service providers. Narrative correspondence involves the gathering of written stories (or narratives) from participants around a pre-defined theme. This approach is particularly effective for gaining an understanding of an individual's experience of events in his/her own words and where there is little existing evidence around a topic area. Researchers using this approach have demonstrated its usefulness in investigating hard to reach groups such as parents of young people with cancer (Grinyer, 2004), disabled people (Thomas, 1998), chronic illness in mid-life women (Kralik et al, 2000), victims of violence in developing countries (Meth, 2003), and older people (Milligan, 2005). As these studies have demonstrated, this approach can offer an empowering form of social research, in that it places a greater degree of control over the shape and content of information that the participant chooses to share compared to many other approaches. Narratives are both personal, in that they are embodied within a specific individual, and social, in that they take their narrative from the context within which they are embedded (Frank 1995). This approach was particularly appropriate for respondents who, as active care-givers, were likely to face (potentially multiple) demands on their time and possible fatigue. It also afforded some mitigation of the demands of participating in research as it enabled participants to decide when and how they relayed and shared their experiences. 
Following ethical approval, an initial call for participants was sent out through carer groups, relevant third sector organisations and adult social care services. Adverts were also placed in local libraries, community centres and newsletters. Interested individuals were sent an information sheet along with a consent form and a list of narrative prompts to help them structure their narrative (see Figure 1). It was made clear, however, that participants were free to include any additional issues they felt were important in telling their story.

\section{INSERT FIGURE 1 HERE}

The only inclusion criteria were that participants should be male, over 50 years of age and either currently caring for a spouse or partner in the north west of England or had done so within the previous six months. Whilst it was not possible to assess the exact number of written narratives that would be returned, past experience suggested that around 15-20 narratives would be gathered within a three month period. Overall, 19 OMCs responded, with a total of 15 older men finally submitting narratives. Whilst participants were asked to frame their submission around the narrative prompts, they were free to write as little or as much as they wanted and to structure their narrative however they liked. To ensure inclusion of those who might find it difficult to give a written narrative, the option of submitting an oral (audio recorded) narrative was offered. Two individuals took up this option and their narratives were transcribed verbatim. Submitted narratives varied in length from between a few pages of handwritten text, five to six pages of typewritten narrative, to 10-15 pages of transcribed oral narrative. Written narratives were submitted either by post $(\mathrm{N}=2)$ or electronically $(\mathrm{N}=11)$. In addition to the narratives, we undertook nine interviews with a range of service providers from the same geographical location. Service providers were drawn from the statutory and third sectors, to include social workers, carers' health and support workers and a dementia 
advisor. These interviews were designed to gain an understanding of the extent to which the assessment of carer needs and support - and the provision of services - took account of gender. They also sought to explore whether providers perceived any differences in how older men performed care in comparison to older women carers.

All data were transcribed in full and where audio narratives or interviews were taken, transcripts were returned to the participants for confirmation. Transcripts were then content analysed. Initial open codes were identified by the researchers using constant comparison techniques. Emergent themes were checked for reliability through a process of peer review in which both researchers checked and agreed emergent categories. Where disagreement occurred we returned to the data to agree the final themes. The final coding thus emerged though a process of iteration. Separate themes were developed for the data from unpaid carers and care providers, with a common gender-specific category. This technique ensured that codes derived from the data itself rather than being developed a priori.

\section{Participants}

Participants ranged between 56 - 89 years of age with a median age of 69.5 years. All cared for their wives (one of whom had recently died). Three participants additionally cared for: a mother, a mother-in-law and an autistic grandson. The cared-for wives ranged from 55 to 90 years of age, with the median age being 67.2 years. The length of time participants had cared for their wives ranged from 10 months to 30 years, with a median of 9.9 years.

All but two of the OMCs were either retired or had given up working to care for their wives full-time. One OMC worked as a part-time taxi driver and one as a part-time gardener fitting their working hours around available respite care. Participants came from diverse 
backgrounds ranging from a retired farmworker and factory worker to a retired GP and a Managing Director of his own business. The range of participants' backgrounds is important as it illustrates that willingness to engage in narrative correspondence is not limited solely to those with a higher educational status. Figure 2 gives brief socio-demographic details of the participants and those they cared for.

\section{INSERT FIGURE 2 HERE}

The remainder of this paper focuses specifically on how older male care-giving is experienced and understood by OMCs themselves, and by formal care providers. We also examine the impact of care-giving on OMC's sense of self and identity as older men. We do so, as a means of beginning to flesh out a counter-narrative to the feminization of care. By this we mean the ways in which care-giving has historically been assigned to, performed by, and understood, as 'women's work'. To be clear, we are not attempting to discount the validity of the feminization of care narrative which still dominates in all but the older population. Rather we wish to draw attention to an emerging shift in the landscape and arrangements of care in older age that, with some exceptions, has largely been ignored, and thereby rendered less visible. Global ageing, a gradual narrowing in the gender gap in life expectancy, and increasing reliance on family members fulfilling carer roles for their relatives, are likely we suggest, to make this an issue of increasing importance in coming decades.

\section{The construction of care and masculinity amongst older men:}

The social and political construction of care as a gendered concept has received much attention across the social sciences. Care, as both physical and emotional labour, falls 
disproportionately on women, who also undertake the bulk of paid care-work, which is frequently undervalued and underpaid (Arber and Ginn 1995; England, 2005; Kilkey et al. 2010). This has been reinforced by political institutional landscapes that are established and maintained around employment legislation and social support that underpins normative assumptions of women as the primary care-givers (Wiles and Rosenberg, 2003; Milligan, 2009). This is not new, but the shifting landscape of care in older age requires some rethinking of the construction of care as a specifically feminine framed concept, to consider how older men embrace and understand care; and what this means in terms of their sense of self and identity. Given the ingress of men into what has largely been viewed as the highly feminized field of care-giving, understanding how masculinities are constructed and performed by older men who undertake care-work is particularly apposite and timely. Hrzenjak (2013) suggests that while gender stereotypes can be especially persistent at older age, unpaid care-giving nevertheless represents an arena for doing alternative masculinities that transgress stereotypical constructions of men and care work. Care work is argued to loosen men's identity formations within the limits of hegemonic masculinity, opening up opportunities for alternative ways of 'being male' and resisting hegemonic masculinity norms. This requires us to unpick the strategies OMCs employ to negotiate their masculinity in a feminized field of care; and consider the extent to which this re/shapes how older men address and undertake their caring role. For example, Hrzenjak (2013) maintains that whilst unpaid caring can present men with a challenge to their masculinity, it is one that they address through employing strategies that seek to professionalise - and thereby legitimise the caring role. By drawing attention to the ways in which they bring their educational and professional skills to the caring role, she argues that male carers distance themselves from the notion of care as unskilled labour and those aspects of care that do not belong within this framing (e.g. cooking, cleaning). In this way, unpaid care is reconstructed as a 'manly task' 
requiring strength, skill or technical 'know how'. By emphasising care as professional work, older men are seen to disassociate themselves from 'feminine ways of doing care'. Others maintain that male carers negotiate preconceptions about care and masculinity by emphasising the 'man-specific' qualities required for the job - such as having stronger authority, greater physical strength (for lifting and handling etc.). In doing so, they either distance themselves from the nurturing aspects associated with feminine care (Hanlon. 2012), or construct nurturing and emotional labour as part of a professional approach. This conceptualisation of how older men frame male care-giving in relation to their masculinity, whilst interesting, does suggest that it is being interpreted within a set of fixed gender norms. As we discuss below, others would argue for a more nuanced approach.

Reference to masculinities, prior educational and professional skills also brings into focus the notion of intersectionality - a concept that allows for the understanding of gender differences as mediated and transformed by other categories of disadvantage such as class and ethnicity. Work on masculinity and intersectionality is rare (Finzch, 2011). In part this is because intersectionality has almost exclusively been applied within a feminist framework in which men have been seen as 'other' - in possession of power and privilege. However, masculinity is not a fixed or uniform concept, rather it is contested terrain that is manifest through the construction of normative hierarchies of masculinities, stratifications and exclusions that can shift and alter over time and space (Connell, 1995: Connell and Messerschmidt, 2005). For example, whilst research on how age and gender constructions jointly influence older men is limited, some theorists suggest that older men can be perceived by others to exhibit a 'diminishing masculinity' compared to that of younger men - one that is often rendered invisible in their everyday lives (see Thompson, 1994; Thompson, 2006). Some commentators argue for the performance of different forms of masculinities in later life, ones 
that are defined by a 'busy' rather than a performance-related work ethic; and connections with others rather than acts of individuation (Ekerdt 1986; Thompson 2006). Calasanti and Bowen (2006) maintain, however, that rather than seeking to imbue care with masculine traits, what we are seeing is a crossing of gender boundaries in spousal care-giving. Here, older male (and female) carers are argued to take on 'gender inappropriate or atypical tasks' (p.257) that their spouses used to perform in order to maintain the care-recipient's sense of self as a gendered being. For OMCs this can include learning to do their wives' hair, apply lotions, put on their make-up and so forth. The reframing of male caregiving within a framework that privileges education and professional skill (and where culture and/or ethnicity may have a very different influences); and where gender boundary crossing may be occurring, suggests that it may be valid to think about intersectionality in relation to OMCs, adding another dimension to debates around the (male) gendering of care.

\section{Exploring older male carers and identity}

OMCs are a hard to reach group, in large part because many do not identify as carers, but see themselves as 'merely looking after their wives'. For some, this is manifest through a stoic approach to care-giving resulting in a refusal to seek or accept support until crisis point is reached. This was evident in a number of the narratives as exemplified by Ben, who had been caring for his wife with dementia for over five years:

I convinced myself that I was coping, and that life could continue in this restricted and quite sterile way indefinitely. Despite the fact that 'bad' days were becoming far more frequent than the 'good', that my fatigue was increasingly expressing itself in impatience, intolerance and harsh words, I steadfastly refused to contemplate outside 
professional help until I found myself walking past the [place]-based office of [organization].

A reluctance by many older men to seek support in caring for their wives was also noted by a number of care providers who noted how this heightened their 'invisibility' to care support services. As one care provider commented:

CP2: A lot of chaps that care for their wives have been very reluctant to receive [hesitates] any kind of service or any kind of support... whereas a lot of women have kind of welcomed us with open arms.

In preparation for the interview, this same care provider had checked back on her referral statistics in order to discuss how many older male carers were in receipt of the care support her organisation provided. She comments:

CP2: I spent the morning looking through my statistics... and seeing just how many chaps had refused....It made me think. Of 101 people referred to the service, only nine were older male carers caring for a spouse.

I: So with those nine, how have you worked with those - have you provided them with a service?

CP2: Well I really haven't for a lot of them, because most of the chaps have refused. ... even when I go out and see them they'll say 'we're fine, we're fine, we're fine'. Women 
sometimes say that too, but not... I mean proportionately they don't... fewer women refuse help than men.

This reluctance to accept support appeared to be connected to OMC's own perceptions that it was their responsibility to support their wives. Care providers suggest that asking for support (particularly from outside the family) may be seen as indicative not only of an inability to cope, but as a perceived failure, as husbands, to provide for their wives. As one care provider commented:

CP3: The difficulty I've found in my experience with older male carers is to have them agree to any form of carers' assessment at all. Quite often I find they don't identify themselves as a carer. It's... you know, 'I'm their husband this is my wife, this is what our vows were about, looking after each other'. They don't... quite often they don't like the label of a carer and therefore see accessing carers' services as something that isn't appropriate to them.

For some OMCs, any inability to cope may be seen to impact on their sense of self and identity as a man. This may be important in understanding how some older men construct their caring roles in relation to their wives, the importance placed on maintaining a provider role within this relationship, and why some OMCs are more reluctant to seek care and support than older women.

In seeking to understand how care-giving activities and the relationalities of caring impact on OMCs' sense of self and identity as men, our narratives revealed a picture that is complex. For some, the gendering of care is wrapped up in their having to learn and undertake household tasks previously viewed by them as falling within the female domain. In relating one OMC’s experience, one care provider remarked: 
CP4: ... she [wife] was sort of losing capacity and he was finding he had to take on more and more responsibility and he just, bless him, didn't have a clue how to work the washing machine...

Peter's narrative also clearly illustrated how, upon his wife's recent death, he found himself completely unprepared to undertake what he saw as 'female' domestic roles such as cooking and shopping, noting that his three daughters had to teach him how to cook (although cooking has now become something of a hobby for him). As other male carers also noted, undertaking everyday food shopping had also been a domestic task undertaken by their wives. In part this reinforces the gender boundary-crossing in spousal care-giving suggested by Calasanti and Bown (2007), however, the picture is perhaps more complex. In taking on these 'gender atypical tasks' some OMCs have sought to bring their professional skills to bear to reorganise and reframe how these tasks are undertaken. One OMC for example, sought to rationalise his care-work, technologising the shopping role through ordering everything online. Others however, described themselves as being 'reasonably domesticated' prior to becoming carers, but framed this through reference to typically male-oriented tasks such as gardening, 'DIY' and driving.

For others, care-giving required adjustment beyond such basic domestic tasks to an engagement with the more personal aspects of care - tasks that even those who may have undertaken some domestic roles had not formerly engaged with. Interestingly care providers indicated that this is often the stage at which OMCs request support as they find themselves unable to cope with the intimate acts of care and the subsequent shift in the wife/husband relationship that this can entail: 
Robert: as a man this [personal hygiene] presents a particular challenge as one felt so intrusive, especially as my wife had always been a private person.

This was not true of all OMCs of course, whilst Edward had a paid care-worker come in to undertake toileting tasks, he did undertake other personal tasks such as dressing, but noted how his hands, rough from the farm work that had been his livelihood, made it difficult for him when handling ladies clothing:

Edward: 'I remember the first pair of tights I tried to put on [his wife] were soon full of ladders, this was an irritation that I had to come to terms with'.

Whilst Edward was willing to undertake more personal care, his narrative highlighted how the separate gendered spheres of work and home that he and his wife had inhabited during their married life had left him poorly prepared for the hands-on cross gender work he now found himself undertaking, commenting:

[his wife] '... did all the bookkeeping plus the everyday running of the farmhouse ... she was up to the task and very good at it which made it unnecessary for me to do anything in the house'.

The wife's declining ability to perform her 'traditional' and life-long domestic role within the home may have a twofold impact that can require negotiation. Firstly, the older man may have to acquire skills he formerly identified as 'women's tasks' but in doing so, seek ways to reaffirm his identity as a man. The growth in the UK of a 'celebrity chef' culture dominated 
largely by men, for example, may act to validate cooking as a hobby that is acceptable to older men. Secondly, the cared-for wife can find herself having to relinquish control over household tasks she may previously have seen as falling within her own personal domain and for some older women, this may be important in terms of how she, herself, affirms her own sense of self and identity within the spousal relationship. As Edward went on to comment:

'...If I had been the patient probably I would have liked being nursed, but the inactivity would have taken its toll. With my wife it's slightly different - I have taken over her domain and she now feels inadequate which I try to take into account.'

Others, however, maintained a more shared and equal role in terms of household tasks throughout their married lives:

Neil: 'I may not be a typical older male carer because I have always been involved in the domestic side of married life. We both worked fulltime and so we shared the domestic chores at home. 'Yvonne' might be cooking the dinner and I might be ironing or vice versa.'

Andrew: 'I am doing the shopping, cooking and cleaning, but have been a house husband before and this aspect is not a problem.'

\section{Care, coping and masculinities}

How masculinities have been played out within the spousal relationship prior to older men taking on the caring role can impact on the extent to which their identities as men are 
re/constructed within the caring relationship. Here we draw on two vignettes to illustrate how OMCs draw on their previous working lives to bring problem-solving approaches to their care-giving, but with very different outcomes.

\section{INSERT FIGURE 3 HERE}

Joseph's narrative included diagrams of his invention and a detailed accounting of his research. His scientific approach to caring for his wife led him to seek endorsement from his GP to apply his approach to caring for his wife, and to seek to publish his findings in academic journals. Despite having his own fitness problems, Joseph noted in his narrative that: 'I have been coping quite well probably because of my scientific drive which has dominated my life'. Thus, through drawing on his education and pre-retirement position as a scientist, Joseph found ways to reinforce his sense of self and masculinity through his current role as an older male carer.

Jeffrey also elicited a problem-solving approach to care that played to skills not just acquired through his previous paid employment as a factory worker, but that built on those skills to find ways in which he could further enhance his wife's ability to self-manage.

\section{INSERT FIGURE 4 HERE}

Whilst it might be anticipated that this would act to enhance his sense of self and masculinity, in fact his narrative goes on to illustrate how it acted to undermine it. Rather than gaining respect for his approach to caring for his wife, his narrative illustrates how this resulted in his masculinity being challenged - not just by other men, but also by his family and women who interpreted the performance of his care-giving in terms of a diminished masculinity: 
Jeffrey: ... 'I've been to classes to learn how to do sewing and things like that .. well a fella' doing that, you're either .. you're sexual orientation's slightly different or you're a weirdo - you know?

\section{AND}

The family say to me, 'you're on permanent holiday, you just sit at home and do this, and you don't work do you?'

His narrative further revealed how OMCs can find themselves isolated, not just within a feminised landscape of care from which they feel excluded, but also by their declining ability to engage in social activities with other older men as a result of their caring role:

'I find that although people will talk back to me, I have to make the first... initial contact to talk to people, usually women. So it's not a good, you're a man out of water, because the women will go for coffee and talk about these girlie things and I'm not invited, I just get the jobs that... I just get the... you know, domestic jobs but I don't get the fun bits. ... 'If anything, I'd like some respect for what I do and parity with other jobs that males do, you know? I've a joiner friend that I manage to go out with from time to time and that's it. It can be difficult if you've no family and you've no job you know? And you don't go to football and you don't do cars - you're struggling you know, for something in common with people.

He further maintained that when being assessed for support, statutory sector assessors showed little interest in who undertook housing adaptations, what support may be needed 
with paperwork or the practical jobs that 'men usually do', rather their interest was in who did the domestic work of cooking, cleaning, shopping and so forth, pointing to institutionalised gendered expectations of both what constitutes cared-for peoples' needs and care-givers spheres of support.

For some, coping was wrapped up in the support and comfort gained from religious and spiritual faith that 'kept their minds positive'. As Andrew noted:

'I need to add that the dimension of religious faith is crucial for me. My massage lady commented that from her experience any kind of faith really makes a difference to how people coped ....there were two dimensions - my own spiritual discipline and experience; and membership of and support by church members.'

For others, coping involved undertaking an active role in finding 'practical solutions' to the challenges of care-giving. We noted earlier how knowledge and experiences gained from previous employment influenced how some OMCs approached the care-giving role. Peter, for example, noted how his training in the armed forces had instilled in him a 'can-do' attitude which meant that despite feeling overwhelmed at times, he just 'got on with the job'. Joseph's scientific background enabled him to look for new ways to address his wife's health problems. Finally, Edward explained how retaining some of his farm work had played an important role in enabling him to cope with his care-giving role, despite his wife's illness:

'We are very blessed in having the farm as it gives 'Rosemary' a nice place to live and I am usually not that far away should she run into trouble. It also gives me an interest so that I have no need to seek respite.' 
For others, coping strategies involved finding new activities that could be undertaken within or in close proximity to the home, such as yoga, running (on a treadmill), dog walking, writing or listening to music in order to keep their minds active and help them cope with the demands of care-giving. Some took up part-time work that they could fit around available respite care and which gave them an interest beyond the home. Alan, for example noted that he started a 'garden tidy' business on retiring 'partly to get me out of the house and partly to keep fit'. Others sought, where possible, to maintain a similar weekly routine to that enjoyed before their wives required care, whilst others had taken a problem-solving approach toward dealing with the symptoms of the illness. Alan, for example, on noticing repeated incidences of money going missing and finding the money neatly stacked in wallets on his wife's room commented:

She did not understand she was doing anything wrong and I instituted a banking system where she has her own money (in a takeaway container!) and a log book; every time she needs money, we take the money out and enter the sum in a log-book. Problem solved!

Others sought to deal with the symptoms of a particular illness by adapting to live with their wife’s reality. As Ben explained:

I've read books on dementia and you have a choice of either persuading her that her reality is wrong, which she won't accept, or you work in an alternate reality and try and bend the truth so that she sort of finds that an acceptable lie that she can work with 
and live with. Like 'I've rung in to say you're sick today' for example. And invent an alternate reality that sort of fits in with hers.

Of course not all older men take such a proactive and practical approach to care-giving. For some, relatively simple things sufficed such as 'Just having a friendly chat helps to pass the day' (Neil), whilst others noted how having support to navigate through what is a complex and often bewildering system of care can prove crucial in enabling the carer to continue caring for longer (this is inevitably true whether the carer is male or female).

\section{Masculinity, emotion and care}

Care-giving involves both practical and emotional support. This distinction is often framed in terms of 'caring for' and 'caring about'. The former encompasses the performance of caregiving through tasks undertaken, whilst the later refers to the emotional aspects of care, that may also include the generalized relational and affective elements of 'being caring'. As Milligan and Wiles (2010) note, while these are helpful distinctions, they can be hard to disentangle in practice.

In this final section we address care and affect in relation to OMCs. As the literature and our own data from care providers suggests, older men often exhibit a stoicism that is manifest in not seeking support, either physical or emotional, until crisis point is reached (McVittie and Willock, 2006; Greenwood and Smith, 2015). Many of the narratives revealed a perception that women are somehow more 'naturally caring'. This reflected care providers observations that women are more likely to have had lifelong openings for gaining competencies in, and the expression of, care through a variety of roles (e.g. care for children, in their paid work, or 
through unpaid community/neighbourhood caring) and hence are more likely to unburden themselves emotionally than men. This was also reflected in Ben's narrative excerpt:

‘... women more likely to support each other than men ... men will not ring up and say 'how are you doing'? etc - it's all couched in terms of how the cared-for is doing. Men just get on with their lives [they] don't like to talk about feelings, emotions, fallibility, things wrong with families etc.'

But even how some men reflect on, and express an emotional discourse of caring can be subtly (an even not so subtly) different from that of women. For example, as the narrative extract below illustrates, rather than expressing his care-giving in terms of love, affection and reciprocity, Robert conveyed his care-giving narrative in terms of conflict and casualties:

'there is only one winner of this conflict, there are unnumbered casualties along the way, and the battlefield is by no means a place for faint hearts. ..I use the metaphor of war quite deliberately because as a carer for my lovely wife I often felt that each day was a battle, that I was beleaguered and devoid of support, lacking the mechanism to cope, and reduced to a reluctant and dispiriting acceptance that the outcome could in no way be influenced by my efforts.'

Ben also suggested that where men do express their emotions, they do so because the setting is: 'giving them permission and a space to do so', pointing to this research project and citing examples of men's refusal to talk about health issues and an attitude of 'what good does it do to talk about feelings?' Despite this perception, many of the narratives were strewn with references to stress, distress, self-doubt, worry, struggle, mental as well as physical 
exhaustion and the need to give and receive emotional support. The narratives also revealed that many of the OMCs felt a real need and desire to have someone to talk to about the issues, but for this to be delivered through professional services (such as a mental health worker or counselling service) rather than friends or relatives. Yet despite this, as Alistair's narrative illustrated, some men are less likely to feel comfortable acknowledging their need for professional emotional support:

'I have recently made contact with [name] carers who have offered emotional support in the form of counselling. The term counselling has something of a stigma attached and I would be reticent to disclose the fact that I am receiving such a service to my male friends and work colleagues. I guess it's a 'man's thing' but it's a real obstacle to overcome - for me at least.'

This, of course, is not true for all, and just as not all women can be characterised as 'naturally caring', not all men struggle with the personal and emotional aspects of caring. Yet for those OMCs who did express the emotional aspects of care, this was almost universally expressed within 'gender permissible' bonds of marital love. These bonds of marital love provided a key motivational force in decisions to continue care-giving for as long as the OMC was physically and emotionally able. As Henry remarked:

With regard to having to undertake personal and intimate care, I can only invoke the spirit of strong love. ...I found no difficulty in persuading myself that in offering this help, the interruption of privacy was at least along the same spectrum as love-making. I am a great believer in the power of love...' 


\section{Concluding Comments}

Whilst our work with care providers has not been the key focus of this paper, there was a clear view from providers at the outset, that assessment and provision is based on need and as such, gender does not figure in their assessment. Interestingly, in almost all cases, discussion revealed that this initial view was followed by a growing reflection during the interview, that despite the greater numbers of older male in comparison to older female carers, OMCs were far more difficult to identify as far fewer came forward to ask for support until crisis point was reached. Further, that even when identified, they were more likely to refuse support than older female carers. Any reluctant, low-level, or resistant help-seeking propensity of older male carers raises significant issues for the current and future management of care.

Yet increased longevity and shifting demographics mean older men are coming to play an increasing role in what has frequently been viewed as a feminized landscape of care. Our understanding of how older men approach care-giving, the coping mechanisms they employ and how care-giving impacts on their identity and sense of self as an older man still remains hazy in comparison to our knowledge of women as caregivers. Existing work around masculinity theory already suggests that masculinities are experienced and played out differently in older age, with emphasis on sociability, business and networks rather than hegemony in the workplace and the accompanying lifestyle (Ekert, 1986; Thompson, 2006). Understanding how care-giving may re/shape older men's sense of self is thus important if we are to understand the impact on their identities as men within this new care landscape. Our work suggests that care-giving can have a significant impact, not just on older men's social networks and opportunities for sociability, but also on how they construct and perform care-giving. This in turn may impact on how OMCs are perceived to perform their masculinities. Jeffrey's narrative is particularly telling in this regard, but so too are those 
narratives that draw out how these older men seek to utilise existing skills to find practical solutions to the 'problems' of care. This recourse to pre-existing skills will, of course, also be true for older female carers, but our point is, that the repertoire of pre-existing skills can be gendered, and thus is likely to be played out in gendered ways in later life caring roles.

Hrzenjak (2013) maintained that OMCs sought to address the challenge of care-giving to their masculinity through employing strategies that sought to professionalise and legitimate the caring role. Our data certainly pointed to some of the ways in which OMCs reaffirmed their masculinity through drawing attention to the ways in which they bring their educational and professional skills to the caring role. However, we would suggest that the picture is more complex that. Contrary to claims that OMCs reaffirmed their masculinity by distancing themselves from those nurturing aspects of care associated with the feminine (such as cooking, cleaning, personal care etc), there was also evidence of what Calasanti and Bowen (2006) referred to as the crossing of gender boundaries, where older male carers are taking on gender atypical tasks. But the picture is complex - our data revealed evidence of that these two approaches to care are not necessarily mutually exclusive. That is, OMC can seek to reaffirm their masculinity through drawing on their educational/work-life skills to shape how they approaching care-giving, but at the same time, take on gender atypical tasks that incorporate both the physical and emotional labour of care. Jeffrey's and Joseph's narratives are good examples of this, but Jeffrey's in particular, also illustrates the external challenges to masculinities that OMCs can face.

The different experiences of Jeffrey and Joseph, but also other OMCs in this study suggest that it may also be important to understand not just how their masculinities are being re/constructed by their care-giving roles but also to address the intersectionality between 
masculinity - and in this case social class. Joseph's masculinity is arguably reinforced by his status as a relatively affluent and highly educated scientist who was able to gain approval and affirmation from the scientific skills he brought to his caring role. Jeffrey, however, as a less affluent and less educated man, found his masculinity being challenged despite taking what is arguably an equally skills-based approach to his caring role. There was also some evidence of intersectionality and faith. For at least four participants (aged between 66-82 years), faith (Christianity and Buddhism) and support from other members of their faith community played an important role in maintaining their ability to care and 'keeping their minds positive. There was less evidence however of the intersection between masculinity, age and caregiving. In this study, age appeared to play a less obvious role in how OMCs approached their care-giving role, their willingness to seek or accept support, or to undertake personal or emotional care. These are, of course, tentative claims - intersectionality was not the core focus of our study and our sample was not only relatively small, but drawn entirely from a white British, heterosexual population. We are thus not able to say anything about the intersectionality between masculinity, race and culture - or of sexuality. However, whilst our conclusions about the connection with age cohort and faith are tentative at best, they do suggest some potentially novel and fruitful areas for future research. 


\section{References}

1. Akpınar, B., Küçuküçlu, O., Yener, G. 2011. Effects of Gender on Burden among Caregivers of Alzheimer's Patients, Journal of Nursing Scholarship, 43:3, 248-254.

2. Arber, S., \& Ginn, J. 1995. Gender differences in informal caring. Health and Social Care in the Community, 3, 19-31.

3. Baker, K. and Robertson, N. 2008. Coping with caring for someone with dementia: Reviewing the literature about men, Aging \& Mental Health, 12:4, 413-422.

4. Calasanti, T. and Bowne, M.E., 2006. Spousal caregiving and crossing gender boundaries: maintaining gendered identities. Journal of Aging Studies, 20, 253-263.

5. Calasanti \& King, N. 2007. Taking Women's Work' 'Like a Man': Husbands' Experiences of Care Work.

6. Connell, R.W. 1995. Masculinities. University of California Press, Berkley, CA.

7. Connell, R.W. and Messerschmidt, J.W. 2005. Hegemonic Masculinity: rethinking the concept. Gender and Society, 19, 829-859.

8. Crocker Houde, S. 2002. Methodological issues in male care-giver research: an integrative review of the literature, Journal of Advanced Nursing, 40:6, 626-640. 
9. Dahlberg, L., Deemak, s., Bambra. C. 2007. Age and Gender of Informal Carers: a population-based study in the UK. Health and Social Care in the Community, 15, 5, 439-445.

10. Davidson, K., Arber, S., \& Ginn, J. (2000). Gendered meanings of care work within late life marital relationships. Canadian Journal of Aging, 19,536-553.

11. del Bono, E., Sala, e., Hancock, R. 2009. Older Carers in the UK: are there really gender differences? New analysis of the individual sample of anonymised records from the 2001 Census. Health and Social Care in the Community, 17, 3, 267-273.

12. Ducharme, F., Le'vesque,L.,Lachance,L., Zarit,S., Vézina,J., Gangbe,M., Caron, C.D. 2006. Older husbands as caregivers of their wives: A descriptive study of the context and relational aspects of care, International Journal of Nursing Studies, 43, 567-579.

13. Ekerdt, D. J. 1986. The busy ethic: Moral continuity between work and retirement. The Gerontologist, 26, 239-244.

14. England, P. 2005. Emerging Theories of Paid Care Work, Annual Review of Sociology, 31, 381-399.

15. Eriksson, H. Sandberg, J., Holmgren, J. and Pringle, K. 2013. His Helping Hands adult daughters' perceptions of fathers with care-giving responsibility. European journal of Social Work, 16,2, 235-248. 
16. Finzch, N. 2011. Historical masculinities as intersectional problem. Gender Forum: an Internet Journal for Gender Studies, Issue 32. Available at:

17. http://www.genderforum.org/issues/historical-masculinities-as-an-intersectionalproblem/editorial/ [accessed: 21/12/15]

18. Frank AW 1995. The Wounded Storyteller: Body, Illness and Ethics. The University of Chicago Press, Chicago and London.

19. Greenwood, N. and Smith, R. 2015. Barriers and facilitators for male carers in accessing formal and informal support: a systematic review. Maturitas, 82, 162-169.

20. Grinyer, A. 2004. The narrative correspondence method: What a follow-up study can tell us about the longer term effect on participants in emotionally demanding research, Qualitative Health Research, 13, 1-16.

21. Hanlon, N. 2012. Masculinities, Care and Equality: identity and nurture in men's lives. Palgrave McMillan, London.

22. Hrženjak, M. 2013. Negotiating masculinity in informal paid care work. International Review of Sociology, 23:2, 346-362.

23. Kilkey,M., Lutz, H., and Palenga-Möllenbeck, E. 2010. Introduction: Domestic and Care Work at the Intersection of Welfare, Gender and Migration Regimes: Some European Experiences, Social Policy and Society, 9:3, 379-384. 
24. Kralik, D., Koch, T., Brady, B. 2000. Pen pals: Cor- respondence as a method for data generation in qualitative research. Journal of Advanced Nursing, 31, 909-17.

25. McVittie, C. and Willock. J. 2006. "You can’t fight windmills”: How older men do health, ill-health and masculinities. Qual Health Res. 16:6 788-801.

26. Meth, P. 2003. Entries and omissions: Using soli- cited diaries in geographical research. Area 35, 195-205.

27. Milligan, C. 2005. Placing narrative correspondence in the geographer's toolbox: insights from care research in New Zealand, New Zealand Geographer, 61, 213-224.

28. Milligan, C. 2009. There’s No Place like Home: People, Place and Care in an Ageing Society, Ashgate Geographies of Health Book Series, Aldershot.

29. Milligan, C. and Wiles, J. 2010. Landscapes of Care, Progress in Human Geography, 36:6, 736-775.

30. Office of National Statistics 2013a. 2011 Census - unpaid care snapshot, available at: http://www.ons.gov.uk/ons/guide-method/census/2011/carers-week/index.html [accessed 31.12.13] 
31. Office of National Statistics. 2013b. What does the 2011 Census tell us about the "oldest old" living in England \& Wales? available at: http://www.ons.gov.uk/ons/rel/mortality-ageing/characteristics-of-older-people/whatdoes-the-2011-census-tell-us-about-the-oldest-old-living-in-england-and-wales/characteristics-of-the--oldest-old--from-the-2011-census.html\#tab-Provision-ofUnpaid-Care [accessed 31.12.13]

32. Ribeiro, O. and Paul, C. 2008. Older male carers and the positive aspects of Care. Ageing and Society, 28:2, 165-183.

33. Ribeiro, O., Paul, C. \& Nogueira, C. 2007. Real men, real husbands: caregiving and masculinities in later life, Journal of Ageing Studies, 21, -313.

34. Sandberg J. and Eriksson H. 2008. From alert commander to passive spectator: older male carers' experience of receiving formal support, International Journal of Older People Nursing, 4, 33-40.

\footnotetext{
35 . Slack, K. and Fraser, M. 2014. Husband, Partner, Dad, Son, Carer? A survey of the experiences and needs of male carers. Carers' trust and Men’s Health Forum. Available at: https://www.carers.org/sites/default/files/male_carers_research.pdf [accessed: 29/04/16].
}

36. Thomas, C. 1998. Disabled women's stories about their childhood experiences. In: Robinson C, Stalker K, eds. Growing Up with Disability. Jessica Kingsley Publishers, London and Philadelphia, pp. 85-96. 
37. Thompson, E.H. 2006. Images of Old Men’s Masculinity: Still a Man? Sex Roles, 55, 633- 648.

38. Thompson, E.H. 1994. (ed). Older Men’s Lives. Sage Publications: London.

39. Wiles, J. and Rosenberg, M. 2003. Paradoxes and contradictions in Canada's home care provision: Unpaid privatisation and private Unpaidisation. Special Issue, Health and Well-Being in Canada, International Journal of Canadian Studies 28, 63-89. 